
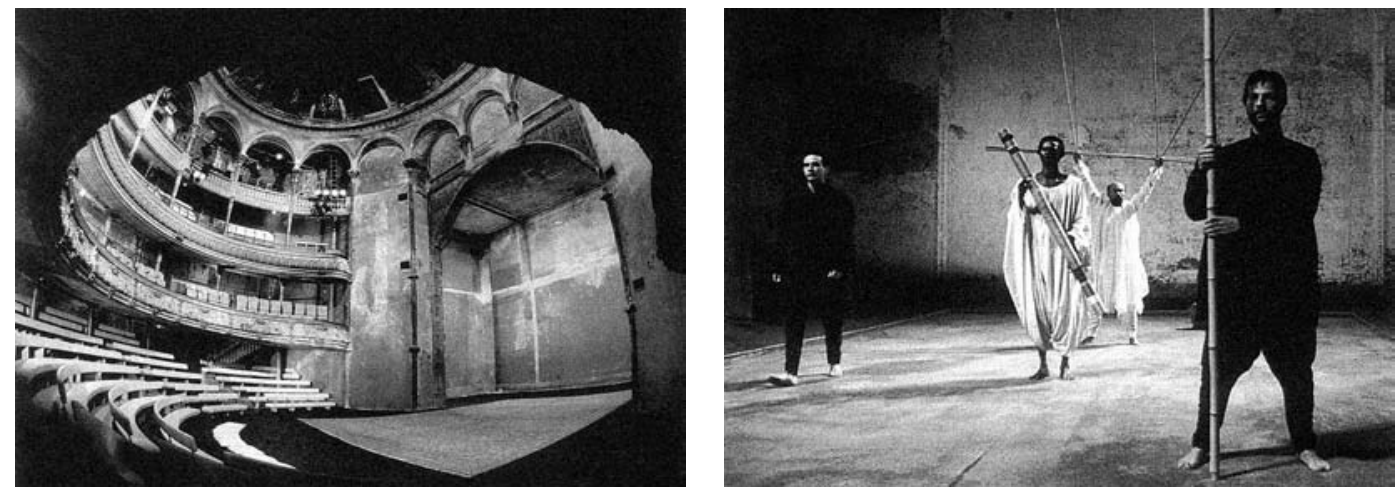

Théâtre des Bouffes du Nord, Paris.

\title{
A crítica de teatro e os novos media
}

\author{
Porter Anderson
}

De vez em quando, naquilo que um actor diz ser "uma boa casa", ele encontra-se com um público que por acaso traz um interesse activo e vida ao seu papel de espectador - esse público colabora. Com essa colaboração, a colaboração de olhos, focalização, desejos, prazer e concentração, a repetição torna-se representação. Então a palavra representação já não separa actor e espectador, cena e público: engloba-os. O que é presente para um é presente para o outro. 0 público também sofreu uma alteração. Veio de uma vida fora do teatro que é essencialmente repetitiva para uma arena especial em que cada momento é vivido de modo mais claro e intenso. O público colabora com o actor, e ao mesmo tempo, para o próprio público, a colaboração vem do palco.

Peter Brook ${ }^{1}$ (1968: 140)

Receio que pensem que sou o fantasma "da crítica futura". Faço o melhor que posso para parecer menos assustador do que aquele espectro final do Scrooge na sua caminhada de uma longa noite até à inevitável aclamação de pé. Mas acredito que venho como mensageiro de novidades algo dificeis tanto para a crítica como para o próprio teatro. E a minha mensagem pode não ser muito diferente da que foi trazida pela entidade misteriosa de Dickens envolta na sua capa preta de capuz. É só isto: fazer as pazes e encontrar um lar entre os novos meios de comunicação é um imperativo, não uma opção. 0 tempo está a esgotar-se.

Nos anos 40 e 50 do século XX, a televisão e mesmo o cinema eram ainda vistos como novidades interessantes e coisas laterais relativamente à vida. Durante a guerra, o noticiário em cinema tinha adquirido uma certa notoriedade, mas a televisão estava a tentar afirmar-se como uma importante fonte de notícias. Estes dois meios de comunicação não pareciam às pessoas, especialmente na Europa e na América do Norte e do Sul, que

constituíssem um perigo para o teatro normal, pelo menos não mais do que a rádio tinha parecido no seu início relativamente à música ao vivo.

De igual modo, o advento da utilização extensiva da Internet no final dos anos 80 e início dos anos 90 do século XX parecia ainda menos um problema para a cena: parecia não competir com as artes e ter apenas uma relevância passageira para o palco, geralmente limitada aos esforços de alguns agentes de bilheteira para vender bilhetes pela Internet (nada de mal com isso, que venha mais poder para eles!).
Os jogos de vídeo online continuavam, acompanhando a chegada da Internet, com o encanto vulgar de uma peça satírica depois de uma trilogia muito longa. Encolhíamos os ombros enquanto as consolas de jogos vibravam com barulhentas imagens de pesadelo, com figuras de armas em riste, com certeza apenas fantasias de violência de adolescentes, não é? Esses jogadores, pensávamos, eram os "jovens em fúria" (Angry Young Men) que, de qualquer modo, nunca iriamos querer num teatro.

Agora, feitas as contas, parece que provavelmente deviamos ter pensado melhor, e mais cedo, sobre a nossa venerável e vulnerável arte do teatro.

Esses jogos de vídeo? A média de idades das pessoas agarradas ao joy-stick é de 37 anos, não os adolescentes barulhentos de 16 anos que gostaríamos de pensar, e são eles que estão a dominar essa "pequena" indústria que vale agora 7, 4 biliões de dólares americanos, ou 6,2 biliões de euros. E será que as mulheres podem ainda salvar 0 teatro dessas actividades estúpidas a que se entregam os homens? Talvez não: a Associação de software de divertimento diz-nos que $43 \%$ dos jogadores são raparigas ${ }^{2}$.

E a Internet? É o mundo sem fios da nossa época, o ambiente crescente das nossas comunicações, da nossa educação, do nosso contexto cultural. Eles hão-de olhar para os vossos vizinhos que continuam a resistir a adoptar a banda larga, como nós olhámos para as pessoas que tinham medo do modelo Ford T ou troçavam da Pininfarina. Quando os jovens do nosso país estão inquietos e discutem o que é que vão fazer para se divertirem, falam porventura de ver uma peça de teatro, ir a um concerto de música clássica ou ao ballet? Ou contemplam antes a possibilidade
10 livro The Empty Space, publicado pela primeira vez em 1968, continua a ser uma das meditações mais influentes do teatro ocidental sobre a arte e a sua proximidade emocional e psicológica relativamente ao público. Uma das suas forças é, de facto, a compreensão de Brook, ao tempo da sua escrita, de que a arte evoluiria para além do ponto em que ele a referenciava: "Quando lerem este livro", escrevia, "já ele estará a ficar fora de moda. É para mim um exercicio, que ficará na página. Mas, diferentemente de um livro, o teatro tem uma caracteristica especial: é sempre possivel começar outra vez" (1968: 140). (Todas as traduções do livro The Empty Space aqui incluidas são da minha responsabilidade. N.T.)

\section{${ }^{2}$ http://} www.recordonline.com/ archive/2006/02/ 06news-kgirlgamers02/06, html. Os dados

referem-se a uma busca sobre jogos de video feita na edição online do Times Herald-Record, a RecordOnline.com. 
Impressões de Pelléas (Impressions de Pelléas), a partir de Claude Debussy,

enc. Peter Brook, claustro do Convento

do Beato, Lisboa,

Março de 1993.

OMahabharato

adaptação teatral de

Jean-Claude Carrière,

enc. Peter Brook,

Thêâtre des Bouffes

du Nord, Paris, 1985

${ }^{3}$ http://www.nytimes.

com/2006/02/18/

business/18music.html

0 New York Times de 18 de Fevereiro de 2006 , relata que o rádio por satélite Sirius tem 3,3 milhões de subscritores, enquanto a Rádio XM, a principal transmissora de música, tem 6 milhões.

São tão caras as

instalações de estações de rádio para ouvintes destes

sistemas de rádio por

satélite que a Sirius dá

conta de gastar 113

dólares por cada novo

subscritor, tendo, apesar de tudo, baixado este ano por comparação a 2004,

quando era de 124 dólares.

${ }^{4}$ http://www.cnn.com/ pipeline/ foi lançado no dia 5 de Dezembro de 2005 e neste momento está disponivel em 25 paises: Alemanha, Arábia Saudita, Austrália, Bélgica,

Brasil, Canada, Chile,

Coreia, Dinamarca,

Emiratos Árabes Unidos, Espanha, Estados Unidos

da América, França Holanda, İndia, Israel, Itália, Japão, México,

Noruega, Polónia, Portugal, Reino Unido, Suécia, Suiça. de ver um filme, ir a uma sala de jogos de vídeo, a um clube de dança ou navegar na Internet?

Sabemos todos como a televisão e o cinema estão por todo o lado. E o aumento da capacidade de uma epidémica penetração global da Internet - para já não falar dos sistemas de rádio por satélite que, só por si, geraram um campo de mais do que 4 mil estações de rádio pela Internet ${ }^{3}$ - significa um mundo mais do que nunca embrulhado, e talvez amortalhado, numa camada atmosférica de divertimento.

É nisto que estamos. A gente de teatro. Gente de discernimento, de análise, de crítica. 0 que é que falta?

Quando nos sentamos para ver algumas das produções preparadas com cuidado a que assistimos aqui em Turim, o que é que não vemos?

A arte do teatro, como muitas outras das suas "irmãs" - música sinfónica, de câmara ou coral, dança clássica ou moderna, artes visuais, escritas e faladas - continua, em grande parte, fechada na sua "caixa". Aquelas quatro paredes, aquele palco, o nosso adorado proscénio, os assentos e o foyer, o acto de se juntarem pessoas fisicamente para verem juntos a representação de um texto. Nós hoje sabemos como pode ser poderosa e importante esta experiência. E também depende de nós hoje, começar a reorientar essa experiência para os novos meios de comunicação - antes que o teatro, tal como o conhecemos, fique total e irremediavelmente ultrapassado.

É isso que falta: essa ligação com o mundo fora dos nossos teatros. A nossa arte é inacessivel.

A medida que crescem os meios de comunicação electrónicos da rádio, cinema, televisão, Internet, os seus jogos e a rede de serviços por satélite, as artes tradicionais do espectáculo ao vivo / experiência em presença estão a ser ultrapassadas a um novo ritmo. Quantos socos mais poderá o teatro levar antes de cair finalmente no tapete para a contagem? Se a rádio foi um, o cinema foi dois, a televisão três, a Internet pode levar-nos até ao dez.

0 problema não é necessariamente que o público seja demasiado restrito. Pelo menos, não é sempre, nem em todos os lugares, nem para todas as artes. Aqui na Europa, vocês saem-se melhor do que nos Estados Unidos. 0 vosso modelo de teatro subsidiado pelo Estado nunca resultou na América. E os nossos criadores teatrais, na sua maioria, nunca aprenderam a tornar possivel a sobrevivência da arte como um bem de consumo, que, é evidente, é a moeda corrente da aprovação yankee.

Contudo, o problema real é que a presença global se revelou de importância crescente para a sobrevivência de qualquer arte, quando as pessoas podem participar nos divertimentos de uma rede planetária a qualquer hora que queiram.
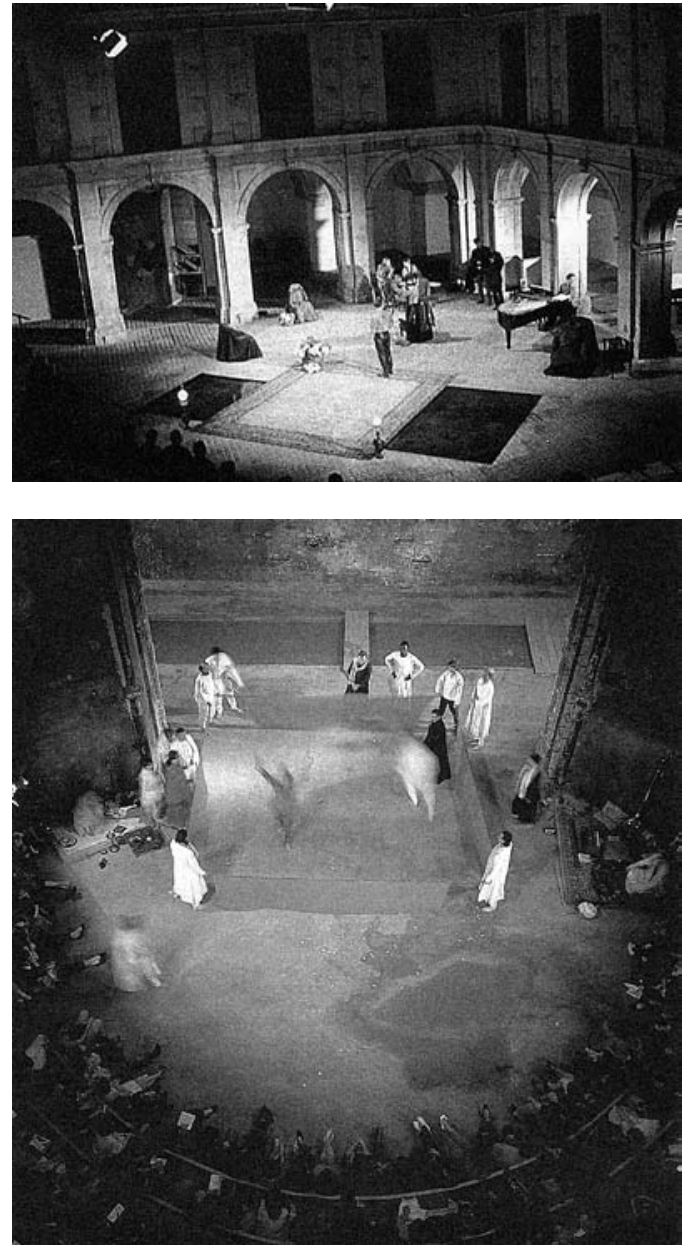

E se o teatro tem de comunicar com o público da rádio e televisão por satélite e com comunidades de jogos pela Internet, e com esses bloguistas muitíssimo atarefados, pode acontecer-nos - a nós, críticos que sempre fomos os seus advogados de defesa - que possamos ajudar a fazê-lo entrar no éter dos novos media.

$\mathrm{Na}$ CNN.com, em Atlanta, o nosso sítio das notícias básicas tem mais de 27 milhões de leitores num dia fraco. Qualquer notícia mais importante - deslizamento de lamas nas Filipinas, um trágico tremor de terra na região de Cachemira, os resultados das eleições palestinianas - pode engrossar esse número até aos 50 milhões de leitores num só dia. Esses leitores estão em todo mundo, não só nos Estados Unidos.

Agora há um novo serviço que podem usar para ver as notícias na Internet no momento em que acontecem, muitas vezes sem a interrupção de um qualquer correspondente ou leitor de notícias - sempre sem anúncios - e a partir de qualquer parte do mundo em que tenhamos uma câmara de filmar. Chama-se CNN Pipeline ${ }^{4}$. Como um oleoduto de petróleo. A tecnologia que desenvolvemos para isto levou 15 meses e envolveu 300 pessoas. Oferece até quatro fluxos simultâneos de notícias sobre 0 acontecimento - alimentação em bruto a partir de qualquer sítio do mundo. Recentemente, fizemos uma sessão experimental em Bruxelas, um tempo de perguntas com Tony Blair na Câmara dos Comuns, uma sessão no julgamento de Saddam Hussein em Bagdad e actualizações dos Jogos Olímpicos em Turim, à medida que acontecem e sem publicidade, no CNN Pipeline. 
Pensamos - e devo frisar que isto está num estádio ainda exploratório - poder criar um "portal" semelhante na Internet para os eventos artísticos. Há muito trabalho a fazer até chegar aí. Pode levar um ano ou mais a fazer. Mas agora temos a capacidade de enviar - através da Internet - um espectáculo do Teatro Nacional em Londres, por exemplo, ao vivo para um público mundial de assinantes que talvez nunca pudesse ir a Londres nem sentar-se naquela "caixa" que se chama Olivier, na margem sul do Tamisa. No momento em que ocorre e em tempo real. Mais tarde, gostamos de pensar, poderemos levar tudo, do teatro, espectáculos de música e de dança até visitas a galerias de arte, leitura de poesia e prosa, a um público globalizado, assim que as negociações de direitos e a logistica da produção estiverem acertadas.

Como digo, é um grande empreendimento. Mas o registo gravado de um acontecimento teatral - talvez pela televisão - nunca traz o carácter de imediatismo de um espectáculo ao vivo. E agora temos capacidade para transmitir imagens de $16 \times 9$, em alta definição, das artes e do espectáculo - graças à Internet - a um público potencial de uma dimensão que tem hoje normalmente o público do cinema, televisão e rádio.

Portanto, agora pensem: qual é o papel do crítico em tudo isto?

Se concordarem que, em qualquer momento, e talvez não tão longínquo, o teatro tradicional vai precisar de "viver" nessa "camada de divertimento atmosférico" que envolve o nosso mundo, então, com toda a certeza, são os críticos da nossa arte que devem preparar a fase que se aproxima. Com certeza, somos os que devem estar aí à espera, preparados com um contexto, história, visão dramatúrgica, conhecimento institucional e puro amor pela arte, para Ihe dar as boas vindas quando ela sair daquela "caixa" em que sempre o temos conhecido.

Já grassa por aí uma batalha no ciberespaço entre meios de comunicação dominantes e "marginais". Os renegados são os sítios de notícias auto-fixadas que não têm revisão jornalística ou avaliação do que relatam, que não têm tradições de restrição e responsabilidade, mas a que não faltam leitores online, desejosos de consumir e difundir os seus boatos como se fossem factos. Vai crescendo uma séria divisão à medida que bloguistas, verdadeiros "craques" em chat-rooms e operações massificadas de correio electrónico, competem, entre leitores de jornais e de televisão, por um público que em tempos sabia claramente como eram crediveis todas as informações que encontravam num jornal diário de grande circulação ou num telejornal. Quer tivéssemos na mão um periódico estatal ou um jornal independente, sabiamos o que tínhamos. Sabíamos como lê-lo. 0 público de hoje que acede à Internetnão sabe. E pode não ter a consciência de como é importante saber, e nem sequer se importar com isso.

0 que acontece se o teatro passar a ser um espectáculo do ciberespaço? Acontece que nós, como críticos e defensores da arte que acompanhamos - a partir da universidade, das redacções dos jornais, ou das distribuidoras online -, nós temos de encontrar energia para ter a certeza de que a batalha terá adeptos. Posso dizer-vos duas ou três coisas sobre o poder da Internet, uma vez que essa é a minha actual base de trabalho. Uma crítica online de um novo CD de música pode, no espaço de poucos minutos, mudar a sua posição na lista das principais distribuidoras de vendas na Internet: Amazon.com, Barnes \&t Noble, Indigo, etc. Algumas das maiores lutas de venda de bilhetes para concertos populares não se passam nas bilheteiras ou nas linhas de marcação por telefone. Essas promoções acontecem na Internet. E quando a Sotheby's se preparava para leiloar umas 70 fotografias muito importantes que o Museu Metropolitano de Arte tinha cedido para venda, a maneira de atrair licitadores em Nova lorque na noite de S. Valentim, em Fevereiro de 2006, foi pela Internet - a Sotheby's colocou cada uma das fotografias num catálogo online, enviou por correio electrónico para os seus licitadores habituais uma notícia sobre o leilão que se iria realizar e a Sotheby's vendeu uma fotografia de Edward Steichen, de 1904, por 2,9 milhões de dólares (2,4 milhões de euros). 0 preço mais elevado alguma vez pago por uma fotografia.

Que respostas temos, então, para justificar a crítica de teatro num mundo de iPods, Pay-per-view e as séries de fugas dos jogos de vídeo intitulados Grand Theft Auto? (Que Deus nos acuda!). Como poderíamos ter pedido a Dorothy Parker ${ }^{5}$ ou Pauline Kael ${ }^{6}$ para competir com Lara Croft $^{7}$ ? Como Ken Tucker nos lembra na Salon Magazine, Kael - debaixo de fogo dos ouvintes das suas primeiras críticas de cinema na Rádio KPFA em Berkeley, na Califórnia - disse durante uma emissão: " Meus caros escritores de cartas anónimas, se pensam que é assim tão fácil ser crítico e tão difícil ser poeta ou pintor, posso sugerir que tentem as duas coisas? Talvez descubram por que há tão poucos críticos e tantos poetas".

Portanto, comecemos por ser bons e pacientes para connosco próprios. Este não é um dilema fácil de enfrentar. 0 que nos espera lá fora são "revistas" de fãs na Internet, aqueles blogues que falam muito e dizem pouco, os chat rooms intermináveis. Por natureza, estas coisas são accionadas e frequentadas por tipos que não gostam de figuras do establishment como são os críticos da imprensa
${ }^{5}$ http://smalland eleganthotels.com/nycl Algoquin_Round_Table. html. Dorothy Parker era uma das famosas criticas que, entre 1919 e 1929, frequentava com regularidade debates públicos no Hotel Algonquin, perto de Times Square, formando o que era nos seus bons tempos a Távola Redonda Algonquin.

${ }^{6} \mathrm{http}: / /$ salon.com/bc/ 1999/02/09bc.html. Pauline Kael foi, entre 1967 e 1991, a critica de cinema do The New Yorker.

http://www.tomraider com/. Laura Croft é a heroina digital da série Eidos dos jogos de computador que incluem a nova lenda Lara Croft Tomb Raider, que saiu em Abril deste ano. 
A conferência das aves (La conférence des oiseaux), narrativa teatral de Jean-Claude Carrière, inspirada pelo poema de Farid Uddin Attar, enc. Peter Brook, claustro do Convento do Beato, Lisboa, Outubro de 1980
${ }^{8}$ N. T.: há aqui uma pequena alteração de sentido relativamente ao texto de Brook, que fala não de teatro moribundo de referência. Muitos não têm conhecimentos nenhuns na área e podem estar ferozmente orgulhosos disso. Podem ter pouca consideração e mesmo desprezo pelas credenciais que conquistámos com trabalho e por currículos brilhantes.

Mas é aí que está o busilis. Acredito que no futuro serão os críticos de teatro que devem encaminhar tanto os artistas de teatro como os seus públicos para se encontrarem na Internet. Acredito que devemos encorajar - nas nossas cidades, comunidades e países - os nossos sítios da Internet e - assim que a tecnologia e a economia o possibilitarem - a real apresentação online de espectáculos de teatro ao vivo.

E acredito ainda que devemos estar preparados para abrir o nosso trabalho, os nossos processos e os nossos corações a esses amadores online através do que os aficionados da Internet chamam "interactividade". Precisamos manter fóruns online em que os leitores desafiem as nossas críticas, sessões de perguntas e respostas em que estudantes e assinantes de teatros possam testar a nossa dramaturgia, e mesmo aulas em tempo real em que apoiemos, como Peter Brook nos ensinou, os nossos teatros e os seus artistas fornecendo um contexto histórico, político e estético para futuras produções e particularmente para novos textos e abordagens experimentais.

0 nosso Georges Banu arranjou-me, em 1990, um bilhete para ir ver uma quarta encenação de A tempestade no teatro Bouffes du Nord, em Paris. Nunca esqueci o modo como ele punha em causa a tradição e transportava esse grande texto para um outro idioma de produção, uma vez que Brook pôs o seu génio no texto que nós julgávamos que conheciamos tão bem - até essa altura.

0 que pode ser a última oportunidade para o teatro se posicionar entre os novos media - e reentrar na consciência cultural da sociedade mais alargada - é um super-salto do espaço de representação mais contido para o mais livre. Para parafrasear Peter Brook, isto podia significar a passagem de um teatro moribundo ${ }^{8}$ para 0 teatro mais imediato que imaginar se possa, em que uma sala com 300 lugares se tornasse numa arena com 3 milhões de lugares, o público local viesse a ser um conclave global e o nosso trabalho se tornasse o "oásis" de que falou Brook, nas vidas de pessoas que nunca na vida

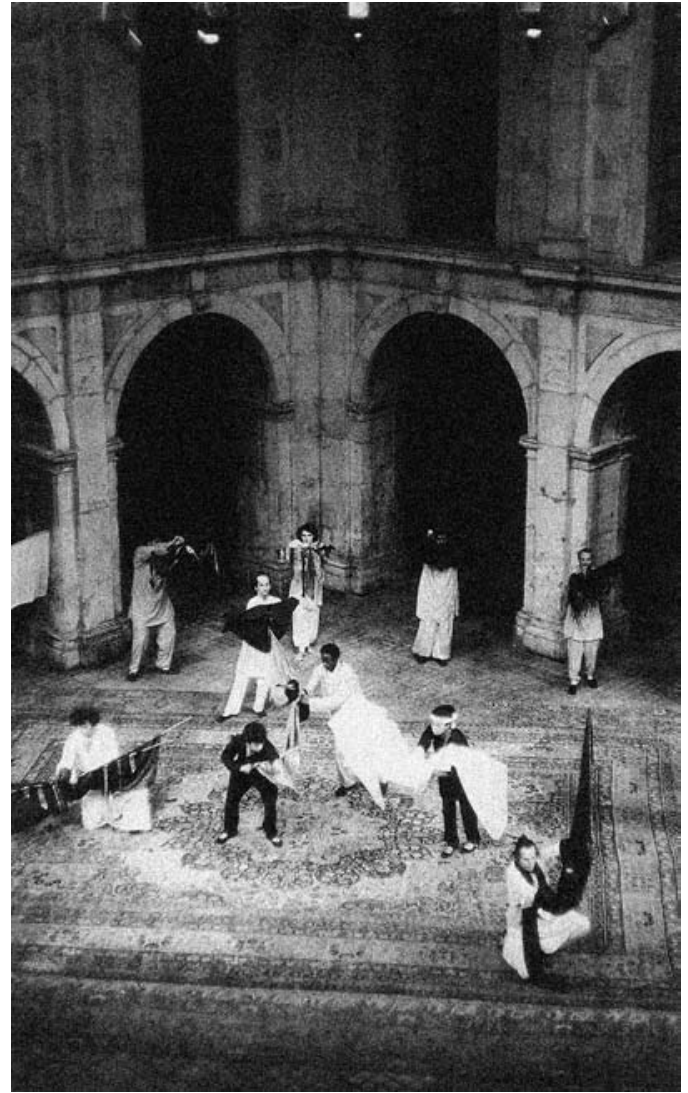

iremos conhecer. As pessoas do meu país podiam estar a ver o teatro dos vossos países. Que bom que seria! "No acontecimento imediato há um resultado inequívoco", escreveu Brook. "É assim que entendo um teatro necessário; um teatro em que entre actor e público há só uma diferença prática e não fundamental".

A tecnologia prática de repente está aí. Que dimensões queremos dar ao nosso "espaço vazio"? Podemos preparar um jovem cibercrítico para atingir um público planetário? Será que teremos a generosidade de permitir que esse numeroso público interaja connosco, como os netizens net citizens (cidadãos da net) - certamente exigirão? Podemos abdicar das nossas construções de pedra e cal e sair para um palco de uma tal dimensão que nem sequer vemos os bastidores da esquerda quando olhamos a partir dos bastidores da direita?

0 artista, diz-nos Brook, "desafia verdadeiramente os espectadores quando é o aguilhão espetado num público que aceita ser desafiado. Ele festeja mais genuinamente com o auditório quando é o porta-voz de um público que tem razões para se alegrar" (1968: 134).

Proponho que entremos na auto-estrada da informação como os trovadores que fomos outrora, para ir ao encontro desses elementos do público - e toquemos a nossa arte nas suas cidades, nos ecrãs dos seus computadores, no grande "espaço vazio" (ainda não tocado) da sua imaginação global.

\section{Referência bibliográfica}

BR00K, Peter (1968), The Empty Space, Harmondsworth, Penguin.

Tradução de Maria Helena Serôdio 